\title{
Erratum to: Fitting an item response theory model with random item effects across groups by a variational approximation
}

\author{
Frank Rijmen • Minjeong Jeon
}

Published online: 23 May 2013

(C) Springer Science+Business Media New York 2013

\section{Erratum to: Ann Oper Res \\ DOI 10.1007/s10479-012-1181-7}

The below acknowledgement was omitted from the original article.

Acknowledgements The research reported here was supported by the Institute of Education Sciences, U.S. Department of Education, through Grant R305D110027 to Educational Testing Service. The opinions expressed are those of the authors and do not represent views of Educational Testing Service, the Institute of Education Sciences, or the U.S. Department of Education.

The online version of the original article can be found under doi:10.1007/s10479-012-1181-7.

F. Rijmen $(\bowtie)$

Educational Testing Service, Rosedale Road, Princeton, NJ 08541, USA

e-mail: frijmen@ets.org

M. Jeon

Graduate School of Education, UC Berkeley, Berkeley, CA, USA 